\title{
A Política da Boa Vizinhança e o Turismo no "The New World Guides to the Latin American Republics" (1945)
}

\author{
La Política de la Buena Vecindad y el Turismo en "The New World \\ Guides to the Latin American Republics" (1945) \\ The Politics of Good Neighborhood and Tourism in "The New World \\ Guides to the Latin American Republics" (1945)
}

\author{
Valeria Lima Guimaraes ${ }^{1}$ \\ Fabíola Araujo da Silva ${ }^{2}$
}

\begin{abstract}
Resumo
Durante a Segunda Guerra Mundial, os Estados Unidos ansiavam por estreitar laços comerciais e culturais com a América Latina. O governo brasileiro, sediado no Rio de Janeiro, por sua vez vislumbrou nessa aproximação o momento ideal para promover-se como o país do futuro e divulgar sua imagem. Essa perspectiva histórica norteia o objetivo geral deste trabalho que é demonstrar a utilização do turismo pela política da Boa Vizinhança e analisar a descrição da cidade do Rio de Janeiro no guia "The New World to the Latin American Republics Volume III", produzido pelo Escritório de Assuntos Inter-americanos (EAI), do governo dos Estados Unidos, destacando o que o EAI desejava que o público americano do norte soubesse sobre a então capital federal brasileira. Para alcançar este objetivo foram desenvolvidos os seguintes objetivos específicos: contextualizar o período no qual o guia foi elaborado; analisar a atuação do EAI como um todo; investigar os itens constantes na referida publicação e os discursos produzidos sobre a América Latina, em especial sobre o Brasil e sua capital. A metodologia baseou-se em pesquisa qualitativa, a partir de análise bibliográfica e de fonte primária. Como resultado, apurou-se que o incentivo ao turismo pancontinental era um fator importante na Política da Boa Vizinhança e que o guia em tela foi um dos frutos dessa política de incentivo às viagens na América Latina, tendo promovido, inclusive, uma imagem positiva do Rio de Janeiro.
\end{abstract}

Palavras-Chave: América Latina; Estados Unidos; Guia turístico; História do Turismo; Política da Boa Vizinhança.

\section{Resumen}

El presente trabajo busca demostrar la utilización del turismo a través de la política del buen vecino y su contexto histórico. La segunda gran guerra había comenzado y Estados Unidos anhelaba estrechar lazos comerciales y culturales con América Latina. El gobierno brasileño, con sede en la ciudad de Río de Janeiro, a su vez vislumbró en esa aproximación el momento ideal para promoverse como el país del futuro y divulgar su imagen. El estudio fue elaborado a partir del análisis del "The New World to the Latin American Republics Volumen III". Serie de guías creada por la Oficina de Asuntos Interamericanos (EAI), para suplir la necesidad de informaciones prácticas sobre los países latinoamericanos. La metodologia bibliográfica fue aplicada con el propósito de analizar y contextualizar la Guía en el período de su publicación; Explicar el momento político por el que pasaban los Estados Unidos y Brasil y investigar cómo la Guía presentaba la ciudad de Río de Janeiro. Como resultado, se constató que el incentivo al turismo pancontinental era un factor importante en la Política de la Buena Vecindad y que el guía fue uno de los frutos de esta política de incentivo a los viajes en América Latina, promoviendo, incluso, una imagen positiva del turismo en Rio de Janeiro.

${ }^{1}$ Doutora em História Comparada. Universidade Federal Fluminense. Niterói, Rio de Janeiro, Brasil. valeriaguimaraes@ig.com.br.

2 Bacharel em Turismo. Universidade Federal Fluminense. Niterói, Rio de Janeiro, Brasil. fabiola_araujo@outlook.com. 
Palabras claves: Estados Unidos; Guía turístico; Historia del Turismo; Política de la Buena Vecindad.

\begin{abstract}
The World War II had begun and the United States longed to strengthen commercial and cultural ties with Latin America. The Brazilian government, headquartered in the city of Rio de Janeiro, for its part took this approach as the ideal moment to be publicized as the country of the future and to promote its picture abroad. This historical perspective guides the general objective of this work, which is to demonstrate the use of tourism by the Good Neighbor policy and to analyze the description of the city of Rio de Janeiro in the guide "The New World to the Latin American Republics - Volume III", produced by the Office of Inter-American Affairs (an US Government agency), stressing that OIAA wanted the north American public to know about the then brazilian federal capital. To achieve this purpose, the following specific objectives were developed: to contextualize the period in which the guide was organized; Analyze the performance of the EAI as a whole; To investigate the items included in this publication and the speeches produced on Latin America. The methodology was based on bibliographic research and primary source analysis. As a result, it was found that the incentive to pan-continental tourism was an important factor in the Good Neighbor Policy and that the guide was one of the fruits of this policy of encouraging travel in Latin America, having also promoted a positive image of the Rio de Janeiro.
\end{abstract}

Keywords: Latin America; United States; Tourist Guide; History of Tourism; Good Neighbor Policy.

\title{
1. Introdução
}

O presente trabalho tem por finalidade apresentar um estudo sobre o "The New World Guides to the Latin American Republics - Volume III'. Aborda um guia turístico elaborado pelo Office of the Coordinator of Inter-American Affairs (OCIAA), ou Escritório de Assuntos Interamericanos (EAI), em português, para suprir a necessidade de informações práticas sobre os países latino-americanos.

A primeira edição do guia foi publicada em 1943. A segunda, data do ano de 1945 e a terceira edição foi publicada em 1950. O material analisado neste estudo refere-se à segunda edição (1945). Esta foi composta por uma série de três volumes, nos quais eram apresentados 20 dos países que integram a América Latina. O primeiro volume apresenta o México e os demais países da América Central. O segundo traz os Andes e os países da costa oeste. No terceiro e último, ao qual tivemos acesso, constam os países da Costa Leste: Argentina, Brasil, Paraguai, Uruguai e Venezuela.

O EAI foi órgão do governo comandado por Nelson Rockfeller, um empresário americano interessado em estreitar laços com a América Latina onde instalou uma filial de sua empresa petroleira, a Standard Oil. Em uma de suas visitas, impressionou-se com as condições econômicas e sociais da região. (ROWLAND, 1947) 
Devido à aproximação com a América Latina, Rockfeller enviou ao governo americano um plano de desenvolvimento para a região, apresentado por Harry Hopkins ao então Presidente Franklin Delano Roosevelt, o qual decidiu executá-lo. No governo anterior já havia interesse em estreitar laços com a América Latina. (ROWLAND, 1947) A partir do plano de Rockfeller, foram viabilizadas ações para fortalecer a política da Boa Vizinhança.

O governo brasileiro, por sua vez, também desejava aproximar-se dos Estados Unidos. Com a guerra, a compra de matérias-primas deste país foi afetada (borracha, ferro, etc.). O Brasil viu a oportunidade de parcerias comerciais e também desejava aproveitar o momento para divulgar a imagem de um país moderno até então desconhecido.

O governo dos Estados Unidos tinha ciência que sua população não possuía conhecimento sobre os países latino-americanos. Para vencer esta barreira cultural e criar o sentimento de solidariedade no hemisfério, criou programas de rádio, filmes com cenário e personagens latinos e artistas consagrados em seus países, dentre eles Carmen Miranda. Foram criadas também produções literárias com esse fim, dentre as quais a série de guias.

O objeto de estudo desta pesquisa é o Guia para as Repúblicas Latino-americanas. Em sua composição estão os itens que eram relevantes para os viajantes da época. Examinaremos o guia fazendo dois recortes: a apresentação do projeto editorial e da América Latina como um todo e, em seguida, da cidade do Rio de Janeiro. Foram definidos como objetivos principais: demonstrar a utilização do turismo pela política da Boa Vizinhança por meio do guia em tela e analisar a descrição da cidade do Rio de Janeiro na publicação, procurando detectar o que o EAI desejava que o público americano do norte soubesse sobre a então capital do Brasil.

A abordagem deste trabalho faz-se qualitativa, pois os resultados esperados não envolvem a quantificação de dados. A metodologia é a análise bibliográfica, com base em materiais publicados em livros, artigos, dissertações, teses e fontes primárias.

\section{A Boa Vizinhança}

A Política da Boa Vizinhança teve início no primeiro governo do Presidente norteamericano Franklin Delano Roosevelt ${ }^{3}$. O termo refere-se à política externa dos Estados Unidos em relação à América Latina nas décadas de 1930 e 1940. Sob esta nova política, os Estados Unidos comprometeram-se a tratar as nações latino-americanas com respeito e evitar interferências em seus negócios domésticos e internacionais (FDR LIBRARY, 2017). Após o

\footnotetext{
${ }^{3}$ Ele foi eleito em 1932 e reeleito em 1936, ficando no poder até 1945, ano de seu falecimento.
} 
seu estabelecimento líderes latino-americanos negociaram com sucesso investimentos na indústria, agricultura, reforma da saúde pública e projetos culturais. Em troca, deveriam atender ao desenvolvimento de bases aéreas, fornecimento de suprimentos para o período da guerra, apoio político e boa vontade contínua.

Esta política teve diversas nuances e controvérsias. Por um lado, foram feitos investimentos financeiros educacionais, na saúde, na agricultura, etc. Por outro, o famoso "American Way of Life" representou uma forma de doutrinação quase imperceptível dos povos envolvidos. Além disso, o conceito de não interferência nas economias latinoamericanas não foi posto em prática, já que o governo americano concedia as benesses da política conforme os seus interesses, em nome "das necessidades de defesa do hemisfério americano." A Política da Boa Vizinhança trouxe também mal-estar no que se refere à construção de representações estereotipadas sobre a cultura e os povos latino-americanos. Apesar de suas deficiências, foi uma referência para o que veio a ser conhecida como a diplomacia do "mandato reverso." O objetivo era informar os Estados Unidos sobre o resto do mundo. (SADLIER, 2012)

O Escritório de Assuntos Inter-americanos, comandado por Nelson Rockfeller, era a agência para a aproximação pela via da cultura entre os Estados Unidos e a América Latina durante a Política da Boa Vizinhança. Para delinear a aproximação dos EUA com o continente foi criado um comitê de políticas dentro do EAI. Este comitê aconselharia na criação de projetos, dentre eles, a criação de um dicionário inglês-português, um guia da América do Sul, intitulado The New World Guides to the Latin American Republics, que será analisado mais adiante, um livro texto para o ensino do Inglês na América Latina e uma revista sobre defesa. (SADLIER, 2012)

O Coordenador do Escritório encorajou o estudo de jornais, revistas, livros didáticos trabalhos literários e programas de intercâmbio cultural na América Latina, como maneiras de compreender os padrões. Acrescentou ainda que as viagens deveriam ser estimuladas de todas as maneiras, assim como intercâmbio educacional. $\mathrm{O}$ resultado ótimo seria forjar a consciência de unidade na América baseado no legado compartilhado como colônias europeias e novas nações independentes. (SADLIER, 2012)

O Presidente Roosevelt e sua equipe sabiam que, além do uso do poder nas relações, precisavam chegar aos corações e mentes dos americanos do norte comuns. Convidá-los a deixar de imaginar os estereótipos negativos dos latino-americanos - eram vistos como 
preguiçosos, suspeitos e retrógrados ${ }^{4}$. Assim, eles começaram sua tarefa usando as ferramentas da imaginação - artes e lazer. Estas abordagens são demonstrações de Soft Power.

Um dos principais conceitos de Soft Power foi definido pelo Historiador Joseph Nye. Ele explica que poder é a habilidade de mudar o comportamento de outros para conseguir o que se quer. Existem três maneiras de exercê-lo: pela coerção (porretes); recompensas (cenouras) e atração (soft power). Este último consiste em fazer com que seus desejos sejam aspirados pelos outros, sem coerção ou recompensas. (NYE, 2010). É relevante salientar que, em anos anteriores a família Rockefeller era conhecida pelo uso do porrete (TOTA, 2000). ${ }^{5}$

$\mathrm{Na}$ indústria do lazer, a Comissão Marítima dos Estados Unidos contratou a Linhas Moore-McCormack. Elas operariam uma frota de dez navios de carga e três transatlânticos da "Boa Vizinhança" entre os Estados e a América do Sul. As linhas de passageiros SS California, Virginia e Pensylvania foram reformadas e renomeadas para SS Uruguay, Brazil e Argentina para a nova rota entre Nova York e Buenos Aires passando pelo Rio de Janeiro, Santos e Montevidéu.

Roosevelt e sua equipe ansiavam por remover a imagem pejorativa da América Latina a partir da produção de filmes. Por meio destes os americanos do norte seriam informados sobre outras características dos vizinhos do sul e, a partir daí começaria uma bela amizade. (AVILES, 2016).

A Divisão de Filmes do Escritório de Assuntos Interamericanos foi organizada para empregar o cinema como uma das três mídias principais em seu programa de informação. A variedade de filmes produzidos nos Estados Unidos proporcionaria a aproximação mais direta com o vasto público no hemisfério. Este fato foi particularmente verdadeiro nas repúblicas latino-americanas, graças às taxas altas de analfabetismo. Foi também um meio útil para introduzir outros aspectos do programa do EAI. Filmes que lidavam com atividades de saúde e saneamento foram amplamente usados tanto como meio de educação popular como para treinamentos. A Divisão de Educação também usava os filmes como ferramenta.

Os planos desenvolvidos na época cobriam atividades como encorajamento de longametragens envolvendo as regiões central e sul da América. Era esperado que certos filmes

\footnotetext{
${ }^{4}$ Estas e outras características foram o resultado de uma pesquisa encomendada por Nelson Rockefeller a George Gallup (SADLIER, 2012)

${ }^{5}$ Em seu outro livro "O Amigo Americano", Tota descreve a trajetória de John D. Rockefeller, patriarca da família, desde o trabalho em um armazém de cereais em Cleveland até o desmembramento da Standard Oil. Um episódio narrado no livro é o da greve dos mineiros de carvão no Colorado (TOTA, 2014). Durante uma manifestação, uma das máquinas incendiou a cidade onde a mina estava instalada. Mais de 40 mineiros e suas famílias pereceram. Este episódio ficou conhecido como o Massacre de Ludlow. (LIBRARY, 2017)
} 
agendados para produção num futuro próximo pudessem ser encenados pelo menos parcialmente na América Latina. A indústria cinematográfica também planejava enviar alguns de seus artistas principais para comparecerem nas premières na América Latina. Outra parte do plano incluía o aumento da cobertura de eventos importantes na América Latina pelos noticiários.

A Divisão de Filmes continuou com seu plano de aumento de produção de materiais relacionados à América Latina. Com o advento da guerra, em comum com as outras divisões de informação, colocou grande ênfase sobre assuntos conectados ao esforço da guerra.

Houve um grande aumento no número de longas-metragens baseados em temas latinoamericanos. Em 1943 notou-se que desde o começo da Divisão foram lançados aproximadamente 30 longas com temas latino-americanos. Além deles, a Divisão também se interessava pela produção de curtas, especialmente os que abordavam as relações dos Estados Unidos com os outros países da América.

Embora cercados de polêmicas, destacamos três embaixadores da Boa Vizinhança na América Latina: Orson Welles, que produziria o documentário "It's All True”, com locações nos Estados Unidos, Canadá, México e Brasil (BENAMOU, 2007); Carmen Miranda, que se apresentou na Broadway (CASTRO apud. SOUZA, 2016) e, posteriormente, atuou em filmes que promoviam a Política da Boa Vizinhança (HIRANO, 2016); e Walt Disney, que viria para baixo dos trópicos com a missão de criar animações que ilustrassem a América Latina como um todo (HERNANDEZ, 2015).

A Política da Boa Vizinhança de Roosevelt foi delineada para ser uma forma de poder sem coerção dos Estados Unidos sobre os países da América Latina. Ainda no artigo de Leite (2002) sobre Walt Disney, verificamos que os Estados Unidos foram bem sucedidos na conquista desse poder: em $1945^{6}$, os governos mexicano e brasileiro fecharam acordos que implicaram o reconhecimento da hegemonia norte-americana no continente.

Daremos destaque a seguir a outra realização do Escritório de Assuntos Interamericanos do governo dos Estados Unidos, publicada sob o título original de The New World Guides to the Latin American Republics.

\section{Os Guias do Novo Mundo para as Repúblicas Latino-Americanas}

De acordo com Ferreira (2011) guia turístico é um canal de informações turísticas. Por sua vez, ela define canal como um tipo de comunicação utilizado por um emissor para

\footnotetext{
${ }^{6} \mathrm{O}$ filme The Three Caballeros, que destacava o Brasil e o México fora lançado no ano anterior.
} 
transmitir informação ao destino ou receptor. Sendo assim, podemos concluir que o guia turístico é um canal de comunicação utilizado por um emissor para passar informações turísticas ao seu receptor, o turista. Sobre o que deve constar em um guia turístico, Perrotta (2011) afirma que "por princípio, espera-se que um guia forneça informações sintéticas, orientadoras e objetivas, tais como endereços, horários e preços e/ou rotas e percursos".

Os guias de viagem constituem um objeto de estudo fecundo para a história cultural em razão de sua responsabilidade nas representações de um lugar e de seus habitantes. (GALANT, 2016). Para Pettermann (2016), “em sua forma mais completa esse gênero literário é composto de três materiais complementares: textos, ilustrações e mapas".

Nesta seção são descritos os itens constantes em The New World Guides to the Latin American Republics. Reproduzimos os objetos de análise de Perrotta (2011) em seu trabalho sobre guias turísticos no Rio de Janeiro no período de 1873 a 1932. Por meio dos resultados obtidos podemos observar a mensagem que o governo americano do norte por intermédio do guia analisado desejava transmitir a sua população.

A tiragem dos guias não é informada na publicação e hoje o material é considerado raro. O exemplar do Volume III estudado neste trabalho (países da Costa Leste da América Latina: Argentina, Brasil, Paraguai, Uruguai e Venezuela), data de 1945, ano da segunda edição da publicação (a primeira, como dito anteriormente, é de 1943). O material foi adquirido em um leilão de obras raras no Rio de Janeiro. Outros exemplares que temos conhecimento encontram-se nas Bibliotecas Baker Business, Fine Arts e Widener da Universidade de Harvard. A Biblioteca Nacional do Rio de Janeiro dispõe de exemplares, porém, indisponíveis para consulta.

Os Guias da edição de 1945 possuem capa dura azul. Na frente, a única inscrição é o título, que está na cor prata. Na lombada constam: o título, o editor E. P. Hanson, o volume do Guia, os países apresentados e a editora, Duell, Sloan and Pearce. A altura é de $20 \mathrm{~cm}$.

Apesar de as primeiras edições terem sido produzidas no período da guerra, a nota da primeira afirma que os guias foram preparados para viagens em tempos normais. Na época, de acordo com o texto de abertura do volume III as viagens estavam seriamente reduzidas. Os editores, entretanto, sentiam que ao desenvolver os guias realizavam um trabalho duplo: auxiliavam na causa do entendimento interamericano e, atuavam também para os Guias do Novo Mundo e para o público viajante para quem eles eram escritos. A seguir, destacaremos as principais seções deste volume. 


\subsection{A preparação}

De acordo com o guia, o aumento das viagens entre os países americanos crescera consideravelmente nos últimos anos e continuaria a se multiplicar com o fim da guerra. $\mathrm{O}$ hemisfério ocidental tornava-se mais unido, há muito carecia de guias compreensíveis. Em reconhecimento a esta necessidade, a Coordenação de Assuntos Interamericanos começou, no início de 1941, a custear a preparação para a publicação dos guias para todos os países da América Latina.

Optou-se por anteceder o guia de cada país com um resumo curto de sua história. Como o material deveria ser condensado, o guia foi escrito primariamente para o viajante comum. O viajante específico encontraria apenas indicações de onde buscar informações (um exemplo deste caso é a seção voltada ao montanhismo).

No que se refere ao turismo cultural, a ênfase foi alocada nas artes, arquitetura, apreciadas com mais assiduidade, e a arqueologia (vista com menos frequência), levando-se em consideração os atrativos locais. Nos guias regionais foi decidido empregar esforços para diversificar as viagens turísticas, no sentido de indicar roteiros mais ousados aos turistas que não se prendiam a hotéis e transportes de alto padrão das cidades cosmopolitas.

Esses guias são uma coletânea de materiais já existentes preparados por escritores e pesquisadores. São também resultado de esforços cooperativos de centenas de pessoas, instituições e agências de vários órgãos do governo americano. A elaboração do guia foi desenvolvida pela intermediação de bibliotecas, arquivos de empresas de transporte, consulados, secretarias de turismo governamentais, guias turísticos existentes em várias línguas, relatórios oficiais, mapas, calendários, circulares de navios a vapor e outras literaturas descritivas. Milhares de itens foram coletados, alguns pela equipe e, às vezes por escritores externos.

\subsection{Utilização}

Nesta seção reforça-se que os guias foram idealizados para o viajante comum. Para informações adicionais, é sugerido que o possível viajante se encaminhe à Divisão de Viagens da União Pan-Americana e ao seu agente de viagens. Como o estudo do Turismo era incipiente neste período, o autor não podia lançar mão de uma tipologia para direcionar ao respectivo turista. Neste volume encontramos referências ao turismo cultural, de aventura, rodoviário e de intercâmbio. 
É discorrido sobre as características de algumas das seções que seriam discriminadas posteriormente. No caso de a informação não ser suficiente ou precisa era indicada uma associação ou órgão competente para prestar esclarecimentos adicionais. A sessão é concluída com um comunicado relatando que a partir de 28 de agosto de 1945 o Secretário de Estado alterou o regulamento de controle de passaporte. Deste momento em diante, os cidadãos americanos estavam habilitados a viajar entre os Estados Unidos e quaisquer países do continente sem levar consigo o passaporte válido.

\subsection{Fundações Históricas e Culturais}

Esta seção foi concebida por Philip Means, Historiador e Mestre em Artes. Sua área de atuação fora em direção à América hispânica, combinando Arqueologia, História e Literatura (BENNETT, 1946). Ele escreve sobre os idiomas, o domínio da fé católica e sua influência no continente, o caráter cultural herdado da Espanha e de Portugal, à exceção do Haiti. ${ }^{7}$ Como a História dos países é analisada individualmente nos guias, ele se atém neste tópico à colonização espanhola e portuguesa como um todo e seu domínio e posterior mestiçagem com as civilizações locais.

\subsection{Arte}

O autor dessa seção do guia foi Robert C. Smith, historiador do barroco brasileiro e português e Professor da Escola de Belas Artes na Universidade da Pennsylvania (DICTIONARY, 2017). Nesta seção, Smith reúne o conhecimento de suas áreas de interesse. Ele conta com riqueza de detalhes a arquitetura baseada nos modelos europeus, porém com influência da arte indígena, o que a deixava com características diferentes das construções europeias.

\subsection{Notas Bibliográficas e Mapas}

O geógrafo Raye R. Platt foi o autor destas seções. Para além destes guias, ele participou de diversos trabalhos sobre a América Latina. (MARTIN, 2015) Na primeira seção

\footnotetext{
7 O Haiti, que localiza-se em uma Ilha juntamente com a República Dominicana foi inicialmente colonizado pela Espanha. Ao verificarem que aquele não era um território rico em ouro, perderam o interesse e aos poucos, abandonaram a ilha. No século XVII, piratas franceses estabeleceram-se na Ilha a fim de tornarem-se fazendeiros. Ao fim de uma guerra na Europa, a Espanha cedeu o território que hoje corresponde ao Haiti para a França no tratado Rystwik. (CORBETT, 1999)
} 
apresenta uma lista complementar com mais informações sobre os assuntos tratados pelos guias. Estas fontes estão restritas a livros lançados para o público em geral e publicações então recentes. Foram listados apenas livros na língua inglesa. A justificativa é que, seria mais simples para pessoas que falassem inglês na América e porque na época havia poucas pessoas que compreendiam os idiomas português e espanhol com facilidade.

No guia, apenas as cidades importantes de algumas zonas centrais são representadas por mapas detalhados. Na seção do Brasil, somente as cidades do Rio de Janeiro e São Paulo foram contempladas. Para Platt, mapas são um item fundamental para se compreender o país que será visitado. Por isso, ele recomenda uma lista de mapas relativos aos países deste volume da série.

\subsection{A União Pan-americana}

O próprio Diretor Geral da União Pan-americana, Leo S. Rowe produziu esta seção. Ele trabalhou na futura Organização dos Estados Americanos (OEA, em português, ou OAS, em inglês) até o fim de sua vida. Era Doutor em Filosofia e entusiasta dos ideais do panamericanismo (OAS, 2017). Em seu texto, ele define a União Pan-americana como uma organização internacional criada e mantida por 21 repúblicas americanas.

A União Pan-Americana, provavelmente após a declaração de Roosevelt sobre 1940 como o "Ano do Turismo na América" (GUIMARÃES, 2012), encarregou-se de promover o turismo nos países americanos. Para este fim, foi criada a Divisão de Viagens. Em contato com órgãos oficiais dos quais recebia informações sobre as condições de viagem e atrativos turísticos em muitos dos países, ela aproximou-se também de empresas de transporte, associações de hotéis e outras organizações interessadas no turismo pelo continente.

Cabe acrescentar que ainda em 1940 foi instituído o Bureau de Viagens dos Estados Unidos. Este órgão coordenava as empresas estatais e privadas interessadas no desenvolvimento de viagens recreativas. Cada vez mais seu programa abordava sobre todos os aspectos de viagem, como o seu desenvolvimento, promoção, importância e os problemas complexos envolvidos em sua execução. O Bureau enfatizou a segurança, valor e a necessidade da viagem pan-americana. Este último teve um papel importante na expansão da viagem entre os continentes americanos (ICKES, 1940).

Voltando ao Guia e à União Pan-Americana, esta publicava monografias e panfletos no esforço de tornar os países do continente americano conhecidos. Um boletim mensal era divulgado em português, inglês e espanhol com informações acuradas a respeito do 
desenvolvimento cultural, econômico e social do continente americano. Por meio desta e outras publicações era promovido o estreitamento dos vínculos culturais e comerciais.

\subsection{Agentes de Viagem}

Fred H. Dietz, Secretário Executivo da Associação Americana de Navios a Vapor e Agências Turísticas ${ }^{8}$, preparou esta seção. Ele explica a imparcialidade no serviço do agente de viagens, já que na época, eles eram remunerados pelas empresas que representavam. Suas indicações baseavam-se no tempo disponível e nos desejos do viajante em relação às despesas. São mencionados os representantes locais dos agentes e sua utilidade na resolução de problemas de língua estrangeira, reserva de quartos de hotel, organização do transporte local, etc. Dietz finaliza convidando o leitor a fazer uso das facilidades oferecidas pelos agentes de viagem.

\subsection{Principais Feriados Católicos}

Aqui se dividem os feriados em móveis e imóveis. São descritas as festas do calendário católico romano. É explicada a mobilidade dos feriados, que são contados a partir da Páscoa. Cita-se o Carnaval, a Quaresma, a Semana Santa, Dia da Ascensão, Pentecostes, Domingo da Trindade e Corpus Christi. Os feriados imóveis mais importantes são relacionados em seguida.

\subsection{Oportunidades Educacionais}

É elaborado um esquema simples indicando as universidades espalhadas pela América Latina e os cursos oferecidos. A lista foi criada com base no relatório da Divisão de Cooperação Intelectual da União Pan-Americana. As recém-criadas escolas de verão também foram relacionadas nesta seção. A Universidade do Brasil, atual Universidade Federal do Rio de Janeiro (UFRJ) disponibilizou esta modalidade de estudo em 1931 e 1932 e planejava fazêlo em 1942. Todavia, a entrada dos Estados Unidos na guerra impossibilitou a realização do projeto.

\footnotetext{
${ }^{8}$ Esta entidade existe até hoje. Em 1946 transformou-se na Associação Americana de Agentes de Viagem. (ASTA, 2017)
} 


\subsection{Estrada Pan-Americana}

Conforme Guimarães (2012), a Estrada Pan-Americana, inaugurada em 1936, foi considerada um dos mais importantes símbolos de integração continental na Política da Boa Vizinhança. A seção do Guia foi elaborada por J. S. Gavigan, membro da Associação Americana de Automobilismo (AAA). Ele resumiu as condições da estrada, de Caracas a Buenos Aires, com dados alusivos ao ano de 1941. Foi recomendado o planejamento prévio da viagem em virtude das chuvas, pois alguns trechos da estrada ficavam intransitáveis. Com exceções, a estrada é adaptada a todo tipo de clima. Para informações adicionais, era recomendado o contato com a Divisão de Viagens ao Exterior da AAA.

\subsection{Montanhismo}

Este tópico foi criado por Anderson Bakewell, também membro da Sociedade Geográfica Americana. Ele discorre sobre o montanhismo apenas na América Espanhola como rico em possibilidades. O enfoque é dado à cadeia montanhosa dos Andes. Para informações mais detalhadas o autor sugere os clubes de alpinismo locais. De acordo com Guimarães (2012), na década de 1930 o Brasil possuía alguns clubes de montanhismo, como o Centro Excursionista Brasileiro, do Rio de Janeiro, e o Parque Nacional de Itatiaia, que abriga o Pico das Agulhas Negras, recebera mais visitantes estrangeiros do que nacionais. Entretanto, o país não é mencionado no guia como local para a prática do montanhismo.

\subsection{Conversão de Pesos e Medidas}

Esta seção trata do sistema métrico que, de acordo com o guia, é utilizado em toda América Latina. Além dele, em alguns países era possível encontrar algumas unidades de medidas antigas provenientes da Espanha. É feito um esquema de conversão de medidas para: comprimento, área, volume, peso e temperatura. Em seguida, são demonstradas as conversões para as unidades da Espanha: arroba, quintal, vara e légua.

O Brasil é destacado como uma das três divisões do Novo Mundo, junto com a América espanhola e a anglo-saxônica. O guia elenca as características que o diferenciam dos demais 
países da América espanhola e afirma que para entender o país faz-se necessário compreendêlas. Ressalta que em nenhum outro lugar é encontrada tamanha diversidade como aqui.

Nesta seção a história é narrada antes do descobrimento. Na tradição irlandesa contase que o nome "Brazil" apareceu nos mapas na Idade Média e uma terra assim chamada foi procurada muito antes do Brasil ser descoberto. O histórico segue com a descoberta de 1500 até a expedição francesa em 1526 na região do Rio da Prata que chamou a atenção de Portugal para o Brasil.

Em seguida é apresentado o período colonial, o crescimento econômico, o movimento de independência por D. Pedro I, o Império, a Proclamação da República (os Estados Unidos do Brasil) e finaliza com o governo de Getúlio Vargas. É importante notar que o texto é concluído com o discurso de que se o regime era uma ditadura, estava livre de supressão, arregimentação, perseguição e o militarismo das ditaduras europeias. As pessoas iam a todo lugar como quisessem. Existia uma total liberdade de culto e, acima de tudo, nenhuma perseguição a minorias religiosas ou discriminação contra elas. (THE NEW WORLD GUIDES..., 1945)

\subsection{A Terra}

A seção seguinte descrevia os aspectos políticos territoriais do Brasil. Gostaríamos de destacar o enfoque na riqueza dos produtos brasileiros. São citados o café, algodão, cacau, milho, arroz, açúcar, frutas, nozes, madeira, borracha e minerais. O café representava praticamente o valor das exportações totais do Brasil, mais da metade para os Estados Unidos. O Brasil produzia cerca de dois terços do fornecimento de café no mundo. Outros materiais como algodão, borracha e minerais também foram negociados para o esforço da guerra, conforme tratado no guia.

\subsection{O Povo}

A formação do povo brasileiro a partir da herança portuguesa, indígena e africana é descrita. É apontado que independente das diversas origens, todos eram considerados brasileiros. Foram citadas características religiosas e o nível de educação. É indicado que o 
povo varia de uma região para outra e descreve-se as características de acordo com as regiões que habitavam.

\subsection{Arte e Arquitetura}

A seção de arte e arquitetura brasileira foi elaborada por Robert Chester Smith, da mesma forma que na primeira parte do guia. Explica aqui que ao contrário da América Latina, a arte indígena não teve espaço no período colonial. Predominava aqui a influência da arte europeia. Ele segue o texto abordando os estilos predominantes ao longo do tempo: o estilo jesuíta, o Barroco, o Rococó e o neoclássico.

\subsection{Informações Práticas}

Aqui se detalham os seguintes itens: como chegar ao Brasil; auxílio aos viajantes; representação dos Estados Unidos no Brasil; fontes de informações locais; clima; vestimenta; saúde; esportes e recreação; moeda; custo de vida e viagem; bancos; transportes; automóveis; companhias aéreas; navegação; serviços postais; telégrafo, cabo e rádio; telefone; lembranças e artesanato; alimentos e bebidas; feriados nacionais; festas e idioma.

\section{O Rio de Janeiro no The New World Guides}

A cidade é descrita de forma lisonjeira. Exibe-se um mapa mostrando a região central. O texto destaca como aspectos históricos a descoberta do porto, a tomada por Villegaignon e a reconquista pelos portugueses. Com a vinda da Família Real, afirma-se que a cidade alcançou um progresso notável. Em 1834, tornou-se a capital do Império. O Guia traz um mapa da cidade, orientando o viajante sob uma perspectiva bastante diferente da atual. Conforme lembra Castro (1999), os mapas turísticos do Rio de Janeiro nas primeiras décadas do século XX enfatizavam o centro da cidade e destacavam o porto, principal portão de entrada dos turistas no país. 


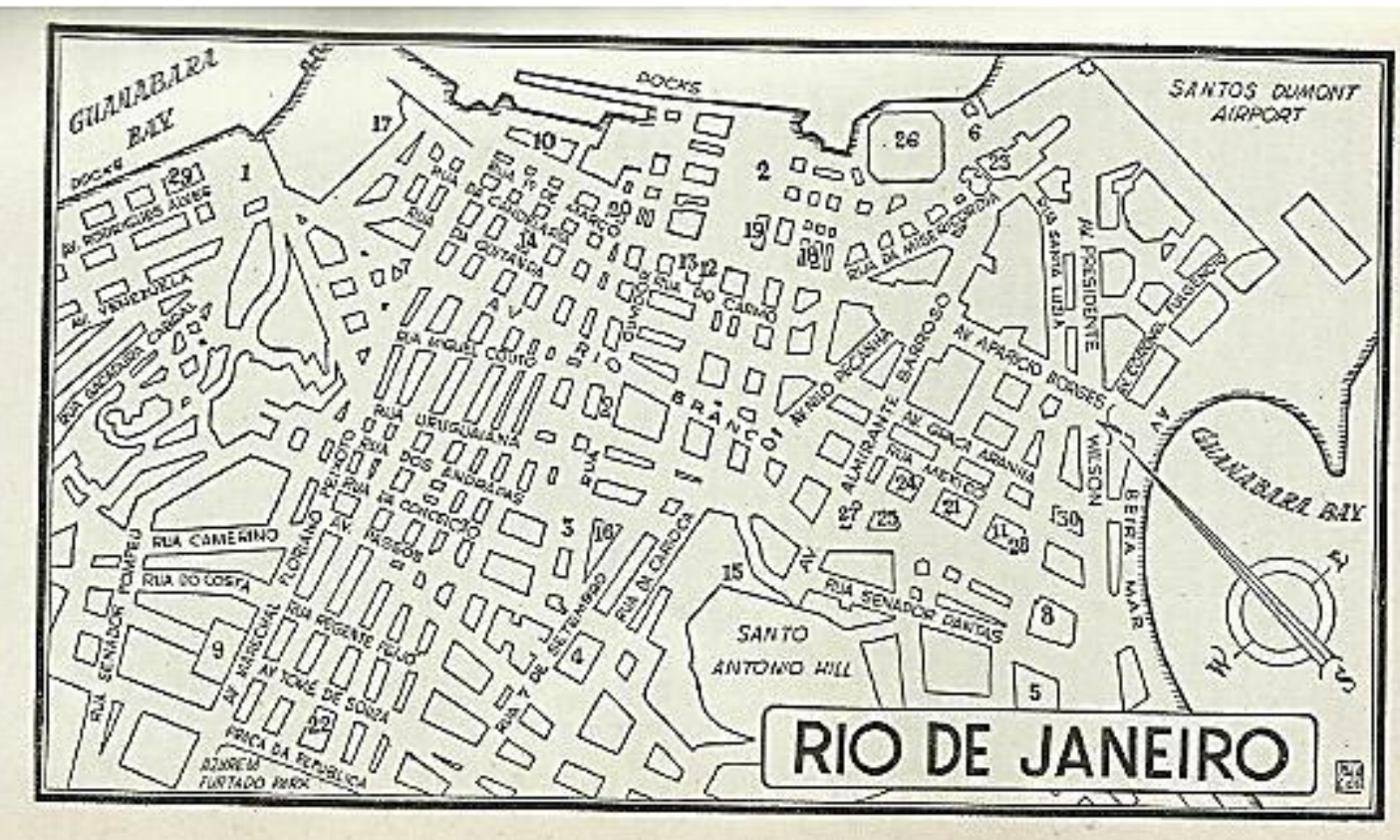

Figura 1 - Mapa do Rio de Janeiro publicado no The New World Guides... (1945, p. 45)

Inicia-se a descrição da cidade de acordo com suas regiões: central, bairros ao redor e os subúrbios residenciais. A região central é tida como o coração comercial da cidade. A impressão que temos ao ler esta parte é que alguém está calmamente guiando o leitor como em um passeio. Subdividem-se os bairros residenciais mediante as direções norte, sul e oeste.

As seções seguintes são dedicadas a categorias de atrativos histórico-culturais, eventos e serviços tais como: Parques e Jardins Públicos; prédios públicos de relevância arquitetônica; igrejas; museus e galerias; bibliotecas; centros de Ensino Superior; teatros, cinemas; festivais e feiras; comércio de souvenires; prática de esportes; correios; serviços de comunicação; bancos; fontes de informações; restaurantes; bares e cassinos e hotéis. As últimas indicam excursões e recomendações de Ilhas na Baía de Guanabara.

\section{Breve análise do Guia}

Conforme mencionado anteriormente, o trabalho de Perrotta (2011) serviu como inspiração para este estudo. Trata-se de uma análise de guias do século XVIII e início do século XIX que pretende demonstrar quando e como se deu a constituição do Rio de Janeiro como destino turístico. Para responder seus questionamentos a pesquisadora analisou os guias de acordo com as categorias que descreveremos e utilizaremos aqui. No momento da análise de The New World Guides to the Latin American Republics, nos deparamos com algumas categorias não aplicáveis ao nosso trabalho. 
A seguir as características analisadas por Perrotta (2011) que aplicamos ao guia:

Contextualização: o guia foi concebido na década de 1940, no período da II Guerra Mundial, quando o governo americano do norte ansiava por aproximar-se da América Latina.

Apresentação: o material estudado integra uma série de três guias que, juntos, expõem a América Latina. No caso do Rio de Janeiro, traz um olhar sobre o Centro da cidade.

Quem publica: Editora Duell, Sloan and Pearce. O ápice de suas publicações ocorreu entre 1940 e 1960. Apesar de não ser especializada neste gênero de literatura, publicou outros guias turísticos.

A quem se dirige: ao público americano do norte.

Estrutura, conteúdo e linguagem: quase em sua totalidade, é composto por textos descritivos. Em duas seções (oportunidades educacionais e conversão de pesos e medidas) apresenta esquemas para simplificar o conteúdo para o leitor.

Características da produção gráfica: reproduzimos os aspectos citados no trabalho da referida autora. O livro possui capa dura, utiliza apenas um tipo de fonte e, salvo os mapas, não apresenta imagens no corpo do texto.

Iconografia: não consta. Acreditamos que, por tratar-se de uma produção patrocinada pelo governo e inserida em uma série de políticas com vistas à aproximação entre países, optou-se por não usar imagens por este meio, já que, anteriores à produção do guia, houve uma extensa produção de ícones apresentando a América Latina.

Mapas: o guia regional (Brasil) dispõe de três mapas: Estradas rodoviárias e ferroviárias brasileiras, Rio de Janeiro e São Paulo.

Publicidade: contém temas diversos como companhias aéreas e marítimas, lâmina de barbear, óleo lubrificante, comunicações de rádio por cabo; loja de roupas; banco de investimentos e centro de beleza, com a maior parte dos anúncios enfatizando a integração continental, como no caso da Pan American Airways, que utilizou como slogan a expressão "Symbol of New World Friendship". 
Atrativos da cidade em destaque: estão agrupados em categorias. É dada ênfase aos atrativos culturais.

Orla e banho de mar: não se faz referência no guia.

Hotelaria: Informa-se que a cidade dispõe de hotéis luxuosos, todavia, eram poucos e as reservas deveriam ser feitas com antecedência. Pela localização privilegiada são citados o hotel Glória e o Copacabana Palace, na Zona Sul e, no Centro, o Palace e o Avenida. Em seguida, faz-se uma avaliação dos hotéis classificando-os por estrelas. Compara-se o padrão dos empreendimentos daqui aos de hotéis em outras partes do mundo.

Excursões para outras cidades: Niterói; Mangaratiba; Angra dos Reis; Cabo Frio; Campos; Petrópolis; Teresópolis e Nova Friburgo.

A partir desta breve análise percebemos que apesar da ausência de algumas das características marcantes como iconografia, mapas diversos e fontes diferenciadas para marcar assuntos, o guia cumpre sua função informativa e passa a mensagem de um Rio de Janeiro e um Brasil civilizado, com história, cultura e infraestrutura disponíveis a quem desejasse visitar, acessíveis ao público norte-americano.

\section{Considerações Finais}

Neste trabalho procurou-se investigar os desdobramentos entre a política da Boa Vizinhança e o turismo e analisar The New World Guides to the Latin American Republics Volume III. Em 1943, no período da II Guerra Mundial, o governo americano do norte, por meio do Escritório de Assuntos Interamericanos (EAI) coordenou a produção de uma série de guias turísticos sobre a América Latina.

A partir destas considerações desenvolvemos o objetivo principal para pesquisa: qual era o papel desempenhado pelo turismo durante a Política da Boa Vizinhança e como a atividade é apresentada na sua publicação turística oficial? Os objetivos específicos propostos para esta pesquisa foram: contextualizar o período no qual o referido guia foi elaborado; analisar a atuação do EAI e, investigar os itens constantes na publicação e os discursos por ela produzidos. 
O empenho em aproximar a América Latina dos Estados Unidos e dos americanos do norte tinha um objetivo claro: defesa e fornecimento de materiais estratégicos. Para avançar na guerra, os Estados Unidos careciam de materiais, pois o comércio com seus provedores fora afetado. Assim, por meio do Soft Power (a habilidade em fazer com que o outro compartilhe dos seus desejos), foram desenvolvidas diversas frentes de atuação, as quais destacamos: comercial e financeira, transporte, programas de rádio e filmes (em espanhol e português), programas educacionais e atividades culturais.

Estas ações foram coordenadas pelo Escritório de Assuntos Interamericanos. Por meio de departamentos que surgiam, fundiam-se e separavam-se de acordo com os acontecimentos na guerra, eram delineadas ações para cada programa. O Coordenador desta agência do governo foi Nelson Rockefeller, um empresário que possuía relacionamento direto com pessoas influentes tanto no âmbito governamental como privado. Ele valeu-se desta posição para conduzir e adaptar o Escritório.

Idealizou-se The New World Guides to the Latin American Republics para além do cunho turístico. Era importante informar que a América Latina como um todo se constituía de sociedades civilizadas e detentoras de culturas dignas de serem conhecidas. Um dos desejos de Getúlio Vargas foi realizado: o guia não transmitia a imagem de um país de malandros. São apresentados diversos atrativos culturais, além de outras opções de lazer como a prática de esportes.

Consideramos que os objetivos anteriormente mencionados foram cumpridos visto que localizamos momentos em que o turismo serviu como meio para ações propostas pelo EAI. Por se tratar de um período de guerra, não foram produzidos programas específicos de incentivo. Existiu, entretanto, a criação de condições que favorecessem sua prática, conforme demonstrado no quadro abaixo:

ANO MEDIDA

1940

Ano da viagem na América - estímulo ao turismo doméstico e interamericano.

Criação do Travel Bureau - envolvia órgãos públicos e empresas privadas interessadas no desenvolvimento de viagens de lazer na América Latina. 
1943 Estímulo ao intercâmbio, especialmente educacional.

Lançamento da primeira edição da série The New World Guides to the Latin American Republics.

Permissão para que os americanos do norte viajassem por todo o 1945 continente americano sem necessidade de portar passaporte. Aos estrangeiros que fossem aos Estados Unidos, a retenção do documento também foi descontinuada.

Esperamos que este trabalho estimule pesquisadores a investigar as fontes existentes, porém pouco analisadas, especialmente as que se referem às relações internacionais e arquivos diplomáticos, e que novos autores com novos olhares possam ajudar a elucidar as relações entre turismo na América Latina e os Estados Unidos nesse período, que foram muito ricas, mas continuam ainda pouco conhecidas e estudadas.

\section{Referências}

ASTA. ASTA: Representing Travel Agents and the Traveling Public for 85 Years. Representing Travel Agents and the Traveling Public for 85 Years. 2017. Disponível em: $<$ https://www.asta.org/About/content.cfm?ItemNumber=752\&navItemNumber=11742>. Acesso em: 20 jun. 2017.

AVILES, M. D. FDR's Good Neighbor Policy. 2016. Disponível em: <http://fdrfoundation.org/author/marcelada/>. Acesso em: 27 maio 2017.

BENAMOU, C. L. In Production, 1941-1942. In: BENAMOU, C. L. It's All True: Orson Welles's Pan-American Odyssey. Oakland: Uiversity Of California Press, 2007. Cap. 1. p. 23 60. Disponível em: 〈https://content.ucpress.edu/chapters/10266.ch01.pdf〉. Acesso em: 01 jun. 2017.

BENNETT, W. C. PHILIP AINSWORTH MEANS, 1892-1944. In: American Anthropologist, [s.1.], v. 48, n. 2, p.234-237, 6 abr. 1946. Wiley-Blackwell. http://dx.doi.org/10.1525/aa.1946.48.2.02a00050. 
<http://onlinelibrary.wiley.com/doi/10.1525/aa.1946.48.2.02a00050/pdf>. Acesso em: 15 jun. 2017.

CASTRO, C. Narrativas e imagens do turismo no Rio de Janeiro. In: VELHO, G. (Org.). Antrpologia urbana: Cultura e sociedade no Brasil e em Portugal. Rio de Janeiro: Jorge Zahar, 1999. p. 80-87.

CHICAGO TRIBUNE. This Is "Travel America Year" for Americans. Washington, p. 6. 21 abr. 1940. Disponível em: <http://archives.chicagotribune.com/1940/04/21/page/162/article/this-is-travel-america-yearfor-americans>. Acesso em: 13 jun. 2017.

CORBETT, B. Short and Oversimplified History of Haiti.1999. Disponível em: <http://faculty.webster.edu/corbetre/haiti/history/course/unitone/short.htm>. Acesso em: 15 jun. 2017.

DICTIONARY OF ART HISTORIANS. Smith, Robert [Chester]. 2017. Disponível em: <https://dictionaryofarthistorians.org/smithr.htm>. Acesso em: 15 jun. 2017.jj

FDR LIBRARY. Franklin D. Roosevelt's Presidency: What was the Good Neighbor Policy?. Disponível em: <https://fdrlibrary.org/fdr-presidency>. Acesso em: 16 maio 2017.

FERREIRA, A. da S. . Guias Turísticos Impressos e suas Dimensões de Análise. 2011. 120 f. TCC (Graduação) - Curso de Turismo, Turismo, Universidade Federal Fluminense, Niteroi, 2011. Disponível em: <http://www.repositorio.uff.br/jspui/bitstream/1/1754/1/160 - Amanda Ferreira.pdf>. Acesso em: 15 jun. 2017.

GALANT, I. Le guide de voyage: passage de la référentialité à la littéralité. 2016. Disponível em:

<https://www.academia.edu/28060092/_Le_guide_de_voyage_passage_de_la_référentialité_à _la_littérarité_Séville_France-Espagne_XIXe-_XXe_siècles_>.Acesso em: 14 jun. 2017.

GUIMARAES, V. L. O Turismo levado a sério: discursos e relações de poder no Brasil e na Argentina. 2012. 333 f. Tese (Doutorado) - Curso de História, Universidade Federal do Rio de Jnaneiro, Rio de Janeiro, 2012. Cap. 3. Disponível em: <http://objdig.ufrj.br/34/teses/793565.pdf>. Acesso em: 23 maio 2017. 
THE NEW WORLD GUIDES TO THE LATIN AMERICAN REPUBLICS. 2. ed. New York: Duell, Sloan And Pearce, 1945. (The New World Guides).

HERNANDEZ, P. S. R. Cinema e Política da Boa Vizinhança: A Expedição de Walt Disney ao Brasil. 2015. 168 f. Dissertação (Mestrado) - Curso de História, Universidade Federal do Estado do Rio de Janeiro - Unirio, Rio de Janeiro, 2015. Disponível em: <http://www.unirio.br/cch/escoladehistoria/pos-graduacao/ppgh/dissertacao_pablohernandez>. Acesso em: 14 maio de 2018.

HIRANO, L. F. K. Imagens de "má" vizinhança: It's all true, de Orson Welles, e a desconstrução racial na forma cinematográfica. Revista Política \& Trabalho, João Pessoa, v. 1, n. $44, \quad$ p.125-143, 2016. Disponível em: <http://periodicos.ufpb.br/index.php/politicaetrabalho/issue/viewIssue/1844/72>. Acesso em: 13 jun. 2017.

ICKES, H. Annual Report of the Department of the Interior. Washington: Government Printing $\quad$ Office, $1940 . \quad$ Disponível em: $<$ https://play.google.com/books/reader?id=MccgAQAAIAAJ\&printsec=frontcover\&output=r eader\&hl=en\&pg=GBS.PR2>. Acesso em: 13 jun. 2017.

JULIN, Suzanne. Tourism. In: RYAN, James Gilbert. Historical dictionary of the 1940s. Londres e Nova York: Routledge, 2015. p. 377. Disponível em: $<$ https://books.google.com.br/books?id=TnmsBwAAQBAJ\&pg=PA377\&lpg=PA377\&dq=Fr anklin+D.+Roosevelt+1940+as+Travel+America+Year\&source=bl\&ots=5AvC8Hyi81\&sig=d 9yiZ_OqljoRwNL1Z2EntHzKYKg\&hl=en\&sa=X\&ved=0ahUKEwictL_EwcHUAhXDj5AK HcNKDt4Q6AEIRDAG\#v=onepage\&q=Franklin D. Roosevelt 1940 as Travel America Year\&f=true>. Acesso em: 13 jun. 2017.

LEITE, S. F. Walt Disney: política e indústria do entretenimento. Communicare, São Paulo, v. 1, p.59-70, 2002. Semestral. Disponível em: <https://casperlibero.edu.br/revistacommunicare/communicare-volume-2-edicao-1-1o-semestre-de-2002/>. Acesso em: 14 jun. 2017.

LIBRARY. Colorado Fuel and Iron Corp. 2017. Disponível em: $<$ https://www.library.hbs.edu/hc/lehman/chrono.html?company=colorado_fuel_and_iron_cor p>. Acesso em: 20 jun. 2017. 
MARTIN, Geoffrey J.. American Geography and Geographers: Toward Geographical Science. Oxford: Oxford University Press, 2015. Disponível em: $<$ https://books.google.com.br/books?id=CbG6BwAAQBAJ\&pg=PA681\&lpg=PA681\&dq=R aye+R.+Platt\&source=bl\&ots=_0A0_g4Oq\&sig=Om7cRRbuCvDcpVkNgG8hFjIID7c\&hl=en\&sa=X\&ved=0ahUKEwj0kaPR6trU AhUII5AKHeg-BMgQ6AEITjAJ\#v=onepage\&q=Raye R. Platt\&f=false>. Acesso em: 15 jun. 2017.

NYE, J. Joseph Nye: Global Power Shifts. Oxford: X, 2010. (19 min.), son., color. Legendado. Disponível em: <https://www.ted.com/talks/joseph_nye_on_global_power_shifts>. Acesso em: 13 jun. 2017.

OAS. Culture and tourism. 2017. Disponível em: <http://www.oas.org/en/sedi/desd/ct/>. Acesso em: 14 jun. 2017.

OAS. Dr. Leo Stanton Rowe: The founder of the ROWE FUND the educational loan program of the OAS. 2017. Disponível em: <https://www.oas.org/en/rowefund/TheFounderDrRowe.pdf>. Acesso em: 15 jun. 2017.

OAS. Turismo. 2017. Disponível em: <http://www.oas.org/pt/topicos/turismo.asp>. Acesso em: 13 jun. 2017.

OMT. Organização Mundial do Turismo. Introdução ao Turismo. São Paulo: Roca, 2001. 371 p.

PERROTTA, I. Desenhando um Paraíso Tropical: A construção do Rio de Janeiro como um destino turístico. 2011. 217 f. Tese (Doutorado) - Curso de História, Fundação Getúlio Vargas, Rio de Janeiro, 2011. Disponível em: < http://bibliotecadigital.fgv.br/dspace/bitstream/handle/10438/8997/CPDOC2011\%20Isabella_ Perrotta_CPDOC.pdf?sequence=1\&isAllowed=y >. Acesso em: 18 nov. 2016.

PETERMANN, D. A imagem de Lyon nos guias de viagem (1900-1950): uma abordagem geo-histórica das representações urbanas. Revista do Instituto de Estudos Brasileiros, [s.1.], n. 65, p.120-144, 31 dez. 2016. Universidade de Sao Paulo Sistema Integrado de Bibliotecas SIBiUSP. http://dx.doi.org/10.11606/issn.2316-901x.v0i65p120-144. Disponível em: <http://www.revistas.usp.br/rieb/article/view/125163/122262>. Acesso em: 14 jun. 2017. 
ROOSEVELT, F. D.. Inaugural Address of President Franklin D. Roosevelt. 1933.

Disponível

em:

<https://fdrlibrary.org/documents/356632/390886/1933inauguraladdress.pdf/000f0bd6-6af1-

48c6-a5ce-1be343a5c007>. Acesso em: 16 maio 2017.

ROWLAND, D. History of the Office of the Coordinator of Inter-American Affairs: Historical Reports on War Administration. Washington: Government Printing Office, 1947. Disponível em: <http://pdf.usaid.gov/pdf_docs/Pcaab967.pdf>. Acesso em: 04 jan. 2017.

SADLIER, D. J. Americans All: Good Neighbor Cultural Diplomacy in World War II. Austin: University Of Texas Press, 2012.

TOTA, A. P. O Imperialismo sedutor: a americanização do Brasil na época da Segunda Guerra. São Paulo: Companhia das Letras, 2000. 